\title{
Overview, Challenges and Future Prospects of Drug Information Services in Nepal: A Reflective Commentary
}

This article was published in the following Dove Press journal: Journal of Multidisciplinary Healthcare

\begin{abstract}
Sunil Shrestha, (iD) ${ }^{1,2}$
Asmita Priyadarshini

Khatiwada, (iD) ${ }^{2}$ Sudesh Gyawali, ${ }^{3}$

P Ravi Shankar, (iD ${ }^{4}$ Subish Palaian (iD ${ }^{5}$

'Department of Pharmacy, Nepal Cancer Hospital and Research Center Pvt. Ltd, Lalitpur, Nepal; ${ }^{2}$ Department of Pharmaceutical and Health Service Research, Nepal Health Research and Innovation Foundation, Lalitpur, Nepal; ${ }^{3}$ In-Charge, Drug Information Center, Manipal Teaching Hospital and Associate Professor, Department of Pharmacology, Manipal College of Medical Sciences, Pokhara, Kaski, Nepal; ${ }^{4}$ Department of Basic Medical Sciences, Oceania University of Medicine, Apia, Samoa; ${ }^{5}$ Department of Clinical Sciences, College of Pharmacy and Health Sciences, Ajman University, Ajman, United Arab Emirates
\end{abstract}

\section{Video abstract}

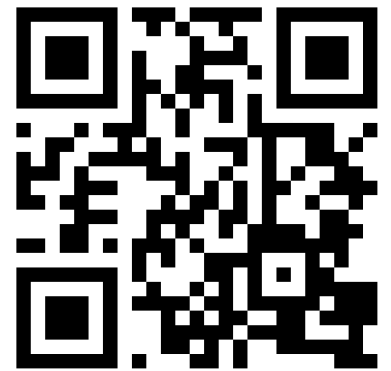

Point your SmartPhone at the code above. If you have a QR code reader the video abstract will appear. Or use: https://youtu.be/QmT4Cqqr9w

Correspondence: Asmita Priyadarshini Khatiwada

Department of Pharmaceutical and Health Service Research, Nepal Health Research and Innovation Foundation, Lalitpur, Nepal

Tel +977-980829195 I

Email asmita.khatiwada2@gmail.com

\begin{abstract}
Drug information center (DIC) or Medicine information services provides impartial, well-referenced, critically evaluated, updated information on various aspects of medications to healthcare professionals and consumers. Medicine information services also contribute to the minimization of medication errors by promoting medication education and supporting pharmaceutical services. The main objective of this reflective commentary is to highlight the recent scenario of medicine information services in Nepal, challenges for DIC, how DICs can be strengthened and future perspectives of DIC. The availability of medicine information in various online drug information sites and numerous applications (apps) have made it easier to assess the information in the country such as Nepal. However, the reliability and validity of such information should be considered before dissemination. DIC plays a crucial role in improving drug safety by aiding clinicians in safer use of medications and promoting adverse drug reaction (ADR) reporting in Nepal. Financial support for operating the DIC efficiently is scarce in Nepal resulting in operational problems. The performance of the medicine information services in the country should be evaluated periodically to ensure the good quality of the service. Steps should be taken by the government, private hospitals and regulatory bodies to sustain the already established DIC and to establish additional DICs in the future to provide quality health care service to the community.
\end{abstract}

Keywords: clinical pharmacologists, drug information, drug information center, evidence-based medicines, hospitals, medicine information services, Nepal, pharmacist, pharmacovigilance, pharmacy practice

\section{Introduction}

Medicine information services (also known as drug information service) is a specialized service that is provided by pharmacists or clinical pharmacists to enhance knowledge of medicines allowing rational prescribing and minimizing medication errors. ${ }^{1}$ Drug Information Center (DIC) provides authentic, individualized, accurate, relevant, unbiased and well-referenced medication information including their indications, adverse effects, and drug safety aspects to the healthcare professionals and patients/consumers. ${ }^{2,3}$ Impartiality and objectivity of medicine information is very important. ${ }^{4}$ Medicine information services have an important role to improve patient outcomes, diminish adverse drug reactions (ADRs) and reduce medication errors. ${ }^{5}$

The drug information (DI) related scenario in Nepal a decade ago was discussed by Anupa et al in the year 2008. However, it provided the contemporaneous scenario of DIC in Manipal Teaching Hospital (MTH), Pokhara and the different functions being carried out. In this article, authors provide the updated scenario of the DICs throughout the country post $2008 .^{6}$ 


\section{Purposes and Importance of DIC}

DIC provides accurate, validated, authentic, unbiased, up to date information on medicines to healthcare professionals and patients/consumers. With the main objective of promoting the rational use of medications, DIC resolves the medication-related queries with evidence-based answers resulting in the safe and effective use of drugs in patients. Additionally, DIC contributes to reducing medication errors by promoting medication education.

Furthermore, DIC has an important role in ensuring the appropriate use of antimicrobials. World Health Organisation (WHO) has defined appropriate use of antimicrobials as

the cost-effective use of antimicrobials which maximizes clinical therapeutic effect while minimizing both drugrelated toxicity and the development of antimicrobial resistance. $^{7}$

With the high incidence of infectious disease in low and middle-income countries compared to high-income countries, antimicrobial resistance has become a dire issue in such nations. ${ }^{8}$ Information regarding antibiotic usage patterns is essential to deal appropriately with the complications that may arise from the use of different antibiotics. ${ }^{9}$ Rational antibiotic usage may be attained with educational interventions and the development of an antibiotic requisition form. ${ }^{10}$ Drug bulletin might be a useful resource for information on antibiotic sensitivity and the usage pattern of antibiotics for different indications within the hospital and community.

DIC plays a crucial role in providing pharmaceutical care services effectively and efficiently. It is accessible to any health care professional for pharmacotherapy related information and doubts and provides objective and unbiased information ensuring the safe use of medications. ${ }^{11}$ By aiding clinicians in safer use of medications and promoting ADR reporting, DIC can play a vital role in improving drug safety. The DIC should be well equipped with all the necessary resources for providing detailed, recent and up to date information on medication queries. To fulfill the common aim of better patient care and rational use of drugs, the ADR reporting system, and DICs should work together. ${ }^{12}$

Therefore, these centers have a positive impact on improving the outcomes of drug therapy. ${ }^{13-15}$ With the provision of unbiased and authentic information, DIC can help in diminishing the occurrence of drug-related complications and assure drug safety to an extent. ${ }^{11}$ DIC acts as a back-up information resource for academics, clinical services, research, and continuing education programs as well.

\section{History of Drug Information Center in Nepal}

In 1994, DIC at Tribhuvan University Teaching Hospital (TUTH) was established to aid the practicing clinicians with information on medications and their appropriate use in different clinical situations. DIC was involved in publishing a bimonthly newsletter highlighting reviews on drug and therapeutics. The center has been engaged in creating public awareness about proper drug use by developing and distributing research-based printed materials like information leaflets, pamphlets, and booklets to the general public. ${ }^{16-19}$

In 1996, Drug Information Network of Nepal (DINoN) was established with the objective of providing high-quality DI and given responsibility for developing and disseminating unambiguous medication information on appropriate use, contraindications, possible ADRs, drug standards, efficacy, and toxicity. ${ }^{5,16}$ DINoN had a total of nine members, five founders, and four ordinary members. ${ }^{17}$ Earlier, DINoN was actively involved in the dissemination of drug information, however later on due to lack of donor funds the operation of the network had diminished. ${ }^{17,20}$ Since its establishment in 2003, DIC at MTH, Pokhara, a tertiary care teaching hospital of Manipal College of Medical Science (MCOMS) had been engaged in different activities associated with DI services, medication counseling services, publication of drug information bulletin, pharmacovigilance activities, contributing to drugs and therapeutic committee (DTC) and continuing pharmacy education (CPE) programs. A quarterly DI and pharmacovigilance bulletin was published by DIC in MTH. ${ }^{6,21}$

Pharmacovigilance activity started in September 2004 through DIC in MTH with a spontaneous ADR reporting program. The activity was envisioned to run efficiently in the coming years. CPE was conducted on a weekly basis in MTH where topics covered were pharmacotherapeutics, drug dispensing and patient counseling. The pharmacists used to accompany clinicians on ward rounds and clarify any doubts or queries. ${ }^{6}$

The Department of Drug Administration (DDA) has been publishing and distributing drug bulletin to health institutions, industries, medical doctors, health personnel, pharmacists and institutions quarterly with updates on 
medications, registration of new molecules with DDA, therapeutic details of medications and regulatory notices. ${ }^{22}$

\section{Recent Scenario of Medicine Information Services in Nepal}

In a developing country like Nepal, accessing unbiased and recent information on medications and therapies is difficult and is still a major limitation. With the closing of certain DICs in Nepal, the smooth functioning of the DICs in Nepal has still not been attained. ${ }^{23}$

The DICs established throughout the country were approached to know the current scenario of the centers. The information was obtained from the authorized personnel of each center either through telephone or in-person meetings. The Table 1 below reflects the current status of the medicine information services in Nepal.

Table 1 shows the DICs in organizations/hospitals which are fully or partially functioning. DDA, the national drug regulatory authority of Nepal has a provision for the provision of drug information and publication of a drug bulletin as the major departmental activity. ${ }^{22,24}$ In MTH, the DIC is actively involved in the training of Pharmacy students (DPharm, BPharm, and MPharm). However, Drug Bulletin has not been published in the last few years. The DIC of the Institute of Medicine (TUTH), in addition to publishing a bulletin, also handles the pharmacovigilance program, communicates with the international narcotics board and monitors advertisements. ${ }^{20}$

A study in Nepal has shown about $40 \%$ of the queries in DIC were regarding ADRs reflecting the importance of DIC in resolving such issues. ${ }^{11}$ Also, the role of pharmacists has been identified well in spontaneous ADR reporting, dissemination of medicine information for optimization of drug therapy and better health management of the patients. ${ }^{25}$

The DICs at B.P. Koirala Institute of Health Sciences (BPKIHS), KIST Teaching Hospital, College of Medical Sciences (COMS), and Resource for Primary Health Care (RECPHEC) are not fully functional. In a few other health institutions in Nepal, medicine information providing centers along with Pharmacovigilance (PV) center is in the planning phase designated to work under the Department of Pharmacology or Department of Pharmacy.

\section{Drug Information Online Sites and Resources}

Many healthcare professionals in Nepal are increasingly using the internet for obtaining medicine information.
With the availability of numerous online sites, it becomes important for the users to identify and assess the respective sites prior to use. ${ }^{26,27}$

WHO Drug Information which was launched in 1987 delivers a synopsis of issues concerning the development of medicines and regulation. WHO Drug Information is published 4 times a year and is mainly targeted at a wider audience of health professionals and policymakers. ${ }^{28}$ Health Inter-Network Access to Research Initiative (HINARI) program, set up by WHO with leading publishers, allows low- and middle- income countries including Nepal to access one of the world's biggest collections of biomedical and health literature. ${ }^{29} \mathrm{Nepal}$ has free access to HINARI which means that the members and students of national universities, professional schools (medicine, nursing, pharmacy, public health, dentistry), research institutes, teaching hospitals and healthcare centers, government offices, national medical libraries, and local non-governmental organizations can access it freely. ${ }^{29}$ Through HINARI, we are able to access high quality journals.

There are many online resources run by a government or nongovernment organization (eg, website of United States Food and Drug Administration (USFDA), American Society of Health-System Pharmacists' Drug Shortage Resource Center ) along with commercial web sites (eg, Medscape, Google Scholar). Proper use of these online assets can enhance the capability of healthcare professionals to obtain information and the decision-making procedure, thus enhancing patient care. $^{26}$ Medicines Complete provides the latest and most relevant medicines information from renowned publications, curated by leading scientists, experts, and researchers. ${ }^{30}$

There are some Nepalese websites and apps including the Nepalese Index of Drug (NIDS), Deo's Pharmacology, NepJol, etc. NIDS, a mobile app providing information on generic medicines, side-effects, precautions, dosage, drug interaction, different brands available in the market, etc. is available for use by doctors, nurses, pharmacists and the consumers. ${ }^{11}$ Healthcare professionals can assess various journals available online for medicine information. Nepal Journals Online provides a number of journals related to both medical and non-medical fields. ${ }^{21}$ There is currently a website https://meropharmacist.com/ run by a team of pharmacists that allows consumers to upload the prescription and obtain an online consultation and also provides free drug information on the basis of a phone call. ${ }^{31}$ 
Table I Current Status of Medicine Information Services in Nepal

\begin{tabular}{|c|c|c|c|c|}
\hline SN. & $\begin{array}{l}\text { Drug } \\
\text { Information } \\
\text { Center/Unit }\end{array}$ & $\begin{array}{l}\text { Approximate } \\
\text { Number of Queries } \\
\text { (Monthly) }\end{array}$ & Current Users & Remarks \\
\hline 1 & $\begin{array}{l}\text { Maharajgunj } \\
\text { Campus, } \\
\text { Institute of } \\
\text { Medicine } \\
\text { (TUTH), } \\
\text { Maharajgunj, } \\
\text { Kathmandu }\end{array}$ & 4 to 5 & Healthcare professionals & $\begin{array}{l}\text { Drug Information Unit is run by the } \\
\text { Department of Clinical Pharmacology. Most of } \\
\text { the queries are from health professionals } \\
\text { regarding drug interaction and ADRs. The } \\
\text { latest issue of the drug bulletin is released last } \\
\text { month and is being published regularly. }\end{array}$ \\
\hline 2 & $\begin{array}{l}\text { Manipal Teaching } \\
\text { Hospital, Pokhara }\end{array}$ & 10 & Healthcare professionals & $\begin{array}{l}\text { DIC provides information to the doctor, nurse } \\
\text { and patients (through the Medication } \\
\text { counseling center). There is no dedicated staff } \\
\text { in the unit and the response to the queries is } \\
\text { not documented. Queries are received } \\
\text { verbally and are responded verbally. General } \\
\text { queries are about medicine availability, cost, } \\
\text { alternative medicine, method of } \\
\text { administration etc. }\end{array}$ \\
\hline 3 & $\begin{array}{l}\text { Dhulikhel } \\
\text { Hospital, } \\
\text { Dhulikhel, Kavre }\end{array}$ & $4-5$ & Healthcare professionals and patients & $\begin{array}{l}\text { There is a separate space for PV and DIC. } \\
\text { Patients of the hospital are counseled properly } \\
\text { and are given the phone number of the DIC. } \\
\text { The patients are asked to call the center for } \\
\text { any drug-related problems or queries. The } \\
\text { patient's problems and queries are addressed } \\
\text { verbally and no documentation is done. The } \\
\text { DIC generally caters to patients and } \\
\text { occasionally to doctors and paramedics. }\end{array}$ \\
\hline 4 & $\begin{array}{l}\text { Patan Hospital, } \\
\text { Patan, Lalitpur }\end{array}$ & $8-9$ & Healthcare professionals & $\begin{array}{l}\text { DIC provides information to the doctor and } \\
\text { other paramedical personnel. There is a space } \\
\text { with books and journals but no dedicated staff. } \\
\text { Medicine related queries are not documented } \\
\text { and are responded verbally. }\end{array}$ \\
\hline 5 & $\begin{array}{l}\text { Nepal Cancer } \\
\text { Hospital and } \\
\text { Research Center, } \\
\text { Lalitpur }\end{array}$ & $5-6$ & $\begin{array}{l}\text { Healthcare professionals (the majority } \\
\text { being hospital pharmacists), cancer } \\
\text { patients in outpatient pharmacy and } \\
\text { family caregivers }\end{array}$ & $\begin{array}{l}\text { There is a separate space for PV and DIC. } \\
\text { Outpatients are counseled properly. Most } \\
\text { queries come from pharmacists working at the } \\
\text { hospital pharmacy. The patient's problems and } \\
\text { queries are addressed verbally and no } \\
\text { documentation is done. }\end{array}$ \\
\hline 6 & $\begin{array}{l}\text { Department of } \\
\text { Drug } \\
\text { Administration, } \\
\text { Bijulibazar, } \\
\text { Kathmandu }\end{array}$ & $\begin{array}{l}\text { The center uses drug } \\
\text { information resources } \\
\text { in evaluating new drug } \\
\text { approvals }\end{array}$ & Regulatory authority staff & It publishes drug bulletin every month. \\
\hline
\end{tabular}

Notes: These numbers of queries in DIC are the ones which we obtained through personal communication from the centers. However, the actual numbers may be even more.

However, assessing the health or medicines information through the online sites needs validation, as the validity of information is a critical issue for reliance on such sites. $^{27,32}$
The reliable e-sources of scientific information like Lancet, BMJ, Springer, etc have paid access to many articles. Getting information with payment may not be a suitable option for a lower-income country like Nepal. ${ }^{33}$ 


\section{Smart Phone, Social Media and Medicine Information Services}

Smartphones with numerous functionalities are easily available. The health care professionals are observed to use smartphones and medical apps for patient care in their everyday practice. ${ }^{34}$ Many medical apps are widely used in clinical decision making. ${ }^{35}$ Smartphones and apps can be useful for management of information on patients, record keeping and maintenance, communication among health care professionals and with patients, consultation in different clinical situations, scientific literature search, gathering of information from guidelines and textbooks, review of the literature, clinical decision making, patient care and monitoring, and self-update about new therapies and indications. Nowadays, healthcare professionals have information on their fingertips which if utilized well can lead to better patient outcome. ${ }^{35}$ With the presence of therapeutic information on clinical conditions and medications, the medical apps aid health care professionals in updating their knowledge and ultimately in improving efficiency and productivity. ${ }^{35}$ However, the validity and reliability of the medication information available in different apps is a topic for debate. Also, the availability of numerous apps might make it confusing to choose the best one. A single app may not contain all the details on the desired subject making it necessary to install many apps in the phone affecting the storage. ${ }^{34,35}$

In Nepal, the penetration of smartphones has crossed $50 \%$ indicating almost half of the Nepalese have smartphones with various applications in their hands. ${ }^{36}$ The electronic recording of the clinical information of patients would be accessible through smartphones and assist in clinical decision making. ${ }^{37}$ The privacy of the patients' health information may be of concern. However, various security techniques are available to safeguard patients' privacy and avoid unauthorized access to electronic records. ${ }^{38}$

In high and middle-income nations, social media has a great impact on the general population. ${ }^{39}$ Even in lowincome countries like Nepal, social media has created its impact. The use of social media increases with increased use of smartphones. ${ }^{40}$ The social media sites can be a useful platform for health care professionals to disseminate healthrelated information to the public, enhance professional connections, upgrade self-awareness regarding new discoveries and news and promote the health outcomes of patients. ${ }^{41,42} \mathrm{In}$ the current digital era, health-related information must be precise, evidence-based and authentic. ${ }^{43}$ However, most of the medicine-related information on social media was shown to be ambiguous or without strong evidence to support the information. ${ }^{44}$ Dissemination of messages through social media should be monitored by the regulatory authorities in the interest of society. ${ }^{44}$ Certain governments and other organizations have taken the initiative to curate the information and provide the general public with authentic, good quality information through health portals. An example is HealthInSite (now termed HealthDirect) of Australia. ${ }^{45}$

Social media like Facebook, Twitter, Google Plus, Pinterest, YouTube, Viber, Instagram, LinkedIn and blogs are widely used in Nepal. The availability of different pages and groups relating to health and medicines on Facebook, Twitter, etc., has increased the use of these social sites. Portals such as Swasthya Khabar Patrika, Nepali health, Hamro health, Hamro doctor, Springboard and several blogs related to health and medicines are the platforms for people to interact on health and medicine related topics. ${ }^{40}$ Portals like HealthIn, Drug information portal by NIH (US national library of medicine) Medline Plus, Medscape, Drugs.com, etc. can be easily accessed by the public for medicine-related information.

\section{Evidence-Based Medicine (EBM) in DI Services}

Evidence-Based medicine (EBM) strengthens health care delivery to the patient and aims to modify patient care according to the patient's particular condition based on the best existing evidence. The evidence ranges from randomized control trials to systematic reviews, meta-analysis, case-control studies, cohort studies, case reports or case series, and in-vitro studies. EBM tends to unite the clinical practice experience with available scientific evidence. ${ }^{46}$ The dissemination of evidence-based information on medicines from DIC is an important contribution to better patient care. It allows for analyzing various options for the management of a particular condition in different patients. Considering interindividual variability among the patients, individualization of medication therapy for the patient based on the scientific evidence can improve clinical decisions. The availability of clinical evidence and timely updates of different therapy and clinical conditions worldwide makes it difficult for the physician alone to finalize the treatment. So, the involvement of DI staff or clinical pharmacists with the treating physician in planning the treatment approach for the individual patient becomes 
necessary. Though there is a huge importance of EBM in Nepal, it is not able to be flourish due to pitfalls. ${ }^{47}$

\section{Medicine Information for Consumers}

Providing information about medicines to consumers (patients or patient caregivers), in verbal, written form or an amalgamation of both is important. ${ }^{48}$ Patients may be prescribed medicines about which they have little knowledge. These medicines can have serious consequences that the patient would not know about or know whom to ask. Consumer Medicines Information (CMI) helps to notify patients and is one constituent of effective medical care. ${ }^{49}$ CMI is standardized, written information for consumers regarding prescription and over the counter medicines which is prepared by pharmaceutical manufacturers. ${ }^{48} \mathrm{CMI}$ leaflets are inserted into medicine packs. The CMI created by pharmaceutical manufacturers is available in the form of a paper (leaflets) or online. There may likewise be a lack of data about interactions with other drugs, including complementary and alternative medicines. ${ }^{49}$ The ultimate merit of CMI depends on fulfilling the need for information about drug therapies and understanding the management approaches of disease conditions by the patients. ${ }^{50}$

Other sources includes direct-to-consumer pharmaceutical advertising (DTCPA) which has developed quickly over the past few years and is currently the most noticeable kind of health communication that the public come across, ${ }^{51,52}$ which can be stated as an effort (frequently via popular media) made by a pharmaceutical company to endorse its prescription products straight to patients. ${ }^{53}$ However, DTCPA is legal only in the United States and New Zealand. The government of Nepal also provides information on medicines to consumers about medicine such as ORS, use of tuberculosis medicines, which can be found in different hospitals, health centers in form of stickers, pamphlets, and other methods.

\section{Challenges for DIC}

The recent, impartial, authentic, technical, objective and scientific information provided by the DIC is helpful in reducing drug-related problems. ${ }^{11}$ DIC and services are at its infancy in developing countries such as Nepal. With the availability of a wide range of information about a particular drug, it becomes difficult to sort the desired information within the given time frame. The overall workflow of DIC may be hampered due to a lack of skilled and trained manpower. Lack of full-time drug information pharmacists in DIC is a challenge for providing better DI services. ${ }^{54}$ Absence of required funding and financial support lead to the unavailability of sufficient human resources in the DIC, ultimately hindering the quality of the services being provided. ${ }^{18}$

Making knowledge and practice about DI service mandatory in undergraduate, and postgraduate syllabus of pharmacy and pharmacology might be useful. ${ }^{21}$ A proper search of the medication information and judgmental evaluation of scientific literature is only possible in the presence of competent pharmacists and clinical pharmacologists in the DICs. Additionally, for appropriate search, interpretation of literature and conveying information to the enquirers, there should be the provision of discussion about plausible outcomes in the particular clinical situation with the enquirers. ${ }^{55}$

Limited availability of recent and updated literature leads to the dissemination of limited and dated information. The availability of literature regarding the research about drugs and other relevant therapeutic information has become a challenge in most developing countries including Nepal. Financial constraints may limit the information search, as access to primary literature (eg journals) and secondary literature (eg abstracting service) is expensive. Additionally, poor documentation, lack of funds and financial support for logistics, inappropriate exchange of information might result in improper functioning of the DIC resulting in biased and limited dissemination of the medication queries. This, in turn, can ultimately result in poor patient health outcomes when the query is meant for patient care thereby highlighting the need for quality service from DIC. ${ }^{6,18}$

Quality assurance is also a key challenge. The performance of DIC should be regularly monitored by the concerned authority in the hospital as well as community settings and should be compared to a good standard. Nepal has a major advantage in terms of access to the WHO HINARI database. ${ }^{56}$ HINARI can be used to access biomedical and scientific literature in resource-constrained settings such as Nepal. ${ }^{29}$

The establishment of DICs should be encouraged within a hospital or in a community and should be fully supported for its better functioning. In the context of Nepal, DICs can be incorporated in hospitals throughout the country starting with the financially stable ones which can sustain the center. Later on, it can be expanded to other health service providing centers. The initiative for the establishment should be taken by the competent pharmacists in the field. They are the ones who can motivate 
and persuade the management to invest in medicine information providing services by highlighting the benefits associated with DICs. If the hospital pharmacy and related services are generating profits and resources for the hospital it may be easier to convince the management.

\section{Strengthening DICs and Services}

Though DI services have been established in different institutes in Nepal in the early 1990s but it is still in the growing phase. Also, services being provided by the existing centers may not be up to the mark. High-quality service should be provided by the DIC and the role of DIC should be recognized for its betterment. This is possible by cyclic evaluation of the services so that the quality is ensured and the areas for further improvement are identified. DIC quality assurance indicators can be found in the literature. However, the key process activities of DIC like a number of queries resolved per day, queries answered within $24 \mathrm{hrs,}$ users' satisfaction, publication of bulletin, continuing education for health care professionals, updating status of drug information sources should be monitored by developing suitable indicators and the performance should be assessed against these indicators. ${ }^{57,58}$ Conducting a survey on the DI services among the receivers of the service can also give an idea of the quality of the service. ${ }^{18}$ Formulation and implementation of Standard Operating Procedure (SOP) can promote the quality of DI service. ${ }^{58}$

The DIC should be accepted within hospital settings as the drug information providers. The health care professionals should approach DIC for any doubts or queries related to drug and treatment therapy.

\section{Future Perspectives}

With an increased number of medications being used in therapy these days, the drug queries will also increase. ${ }^{59}$ An increase in the number of brands of medication and aggressive promotional strategies by pharmaceutical companies leads to the easy availability of biased information to medical practitioners and consumers. ${ }^{11}$ Henceforth, it becomes very essential to provide detailed and recent information regarding these drugs by the healthcare professionals and also the patient to a certain level making DIC highly relevant in the years to come. ${ }^{55}$

Studies have shown that with adherence to the DIC quality assurance protocol, customer satisfaction improved. ${ }^{60}$ The quality assurance protocol for DIC should be made stringent so that it would result in better DI service and ultimately better patient health outcomes. However, young health professionals are disinclined to approach DIC in person. So, the idea of a mobile application software might meet the need of the hour. ${ }^{61}$ Further, DIC can be involved in research by encouraging young researchers in the field of pharmacoepidemiology, pharmacoeconomics and rational use of therapy. ${ }^{21}$ Twenty-four hours DI services can be planned at the national level meeting the increased need throughout the country at low cost.

Easy access to information through smartphones and mobile apps might cast a shadow on DI services as answers for general queries might be obtained effortlessly. Nevertheless, for resolving queries that require critical judgment, analysis and interpretation of the scientific literature, services of DIC are inevitable. So, in developing countries like ours, the role of DIC is important even in this modern era.

\section{Conclusion}

Within the Nepalese health community, there is a necessity for better quality medicine information services. Through the functioning of DIC based on the well-formulated SOP and cyclic evaluation of the services, the quality of the service can be promoted and the sustainability of the existing DICs can be ensured. DIC plays a crucial part in better patient care with the approach of evidence-based medicine. The availability and increased use of smartphones and numerous medical apps by healthcare professionals might ease and promote the delivery of the services by DIC.

\section{Acknowledgments}

The authors will like to acknowledge all the personnel from different drug information centers of Nepal for providing the information.

\section{Disclosure}

The authors report no conflicts of interest in this work.

\section{References}

1. George B, Rao PG. Assessment and evaluation of drug information services provided in a South Indian teaching hospital. Indian J Pharmacol. 2005;37(5):315.

2. Chauhan N, Moin S, Pandey A, Mittal A, Bajaj U. Indian aspects of drug information resources and impact of drug information centre on community. J Adv Pharm Technol Res. 2013;4(2):84-93. doi:10.4103/ 2231-4040.111524

3. Pradhan SC. The performance of drug information center at the University of Kansas Medical Center, Kansas city, USA-experiences and evaluations. Indian J Pharmacol. 2002;34(2):123-129.

4. Khan N, Naqvi A, Ahmad R, et al. Perceptions and attitudes of medical sales representatives (MSRs) and prescribers regarding pharmaceutical sales promotion and prescribing practices in Pakistan. J Young Pharm. 2016;8(3):244-250. doi:10.5530/jyp.2016.3.13 
5. Ali AA, Yusoff SM, Joffry SM, Wahab MSA. Drug information service awareness program and its impact on characteristics of inquiries at DIS unit in Malaysian public hospital. Arch Pharm Pract. 2013;4(1):9. doi:10.4103/2045-080X.111576

6. Chhetri AK, Palaian S, Mishra P. Drug information services in Nepal: the changing perspectives. Kathmandu Univ Med J. 2008;6(1):117-121.

7. World Health Organization. WHO Global Strategy for Containment of Antimicrobial Resistance. Geneva: World Health Organization; 2001.

8. Neill J. Tackling drug-resistant infections globally: final report and recommendations-The review on antimicrobial resistance. Accessed September 4, 2019.

9. Srishyla M, Nagarani M, Venkataraman B. Drug utilization of antimicrobials in the in-patient setting of a tertiary hospital. Indian J Pharmacol. 1994;26(4):282.

10. Shankar RP, Partha P, Shenoy NK, Easow JM, Brahmadathan KN. Prescribing patterns of antibiotics and sensitivity patterns of common microorganisms in the Internal Medicine ward of a teaching hospital in Western Nepal: a prospective study. Ann Clin Microbiol Antimicrob. 2003;2:7. doi:10.1186/1476-0711-2-7

11. Palaian S, Mishra P, Shankar PR, Bista D, Purwar B. Contribution of the regional drug information center towards drug safety. $J$ Nepal Med Assoc. 2006;45(161):216-218.

12. Jimmy B, Jose J, Rao P. Short communication: pattern of adverse drug reaction related queries received by the drug information centre of a tertiary care teaching hospital. Pak J Pharm Sci. 2007;20(4):333-339.

13. Vassilev ZP, Chu AF, Ruck B, Adams EH, Marcus SM. Evaluation of adverse drug reactions reported to a poison control center between 2000 and 2007. Am J Health Syst Pharm. 2009;66(5):481-487. doi:10.2146/ajhp080267

14. Entezari-maleki T, Taraz M, Javadi MR, et al. A two-year utilization of the pharmacist-operated drug information center in Iran. $J$ Res Pharm Pract. 2014;3(4):117. doi:10.4103/2279-042X.145368

15. Hands D, Stephens M, Brown D. A systematic review of the clinical and economic impact of drug information services on patient outcome. Pharm World Sci. 2002;24(4):132-138. doi:10.1023/ A:1019573118419

16. Joshi M, Shrestha B, Shrestha P, Shrestha C, Housley D, Johnson K. Drug information network of Nepal: an innovative approach to the provision of information. INRUD News. 1996;6(2):16-17.

17. M J, Johnson KW, Blum N, Regmi B, Khakurel B. Research-based development of consumer drug information pamphlet at Tribhuvan University Teaching Hospital in Nepal. J Nepal Med Assoc. 2003;41 (144):468-480. doi:10.31729/jnma.690

18. Joshi M. University hospital-based drug information service in a developing country. Eur J Clin Pharmacol. 1997;53(2):89-94. doi:10.1007/s002280050343

19. Mohan JP. Drug information service at teaching hospitals in developing countries. Indian J Pharmacol. 1998;30(1):1.

20. World Health Organization. Medicines in health care delivery, Nepal; 2015. Available from: http://www.searo.who.int/entity/medicines/ nepal2014.pdf. Accessed September 8, 2019.

21. Shankar PR, Mishra P, Subish P, Upadhyay DK. The drug information center at the Manipal Teaching Hospital-Going beyond drug information. Drug Inf J. 2007;41(6):761-768. doi:10.1177/009286150704100608

22. Department of Drug Adminstration. Available from: http://www.dda. gov.np/content/drug-bulletin-of-nepal. Accessed September 8, 2019.

23. Shankar PR, Palaian S, Thapa HS, Ansari M, Regmi B. Hospital pharmacy services in teaching hospitals in Nepal: challenges and the way forward. Arch Med Health Sci. 2016;4(2):212. doi:10.4103/ 2321-4848.196212

24. Ranjit E. Pharmacy practice in Nepal. Can J Hosp Pharm. 2016;69 (6):493-500. doi:10.4212/cjhp.v69i6.1614

25. Khanal S, Poudel A, Sharan K, Palaian S. Oncology pharmacy practice in a teaching hospital in Nepal. J Oncol Pharm Pract. 2010;16(2):75-79. doi:10.1177/1078155209337662
26. Grossman S, Zerilli T. Health and medication information resources on the World Wide Web. J Pharm Pract. 2013;26(2):85-94. doi:10.1177/0897190012474231

27. Shankar PR Subish P, Dubey AK. Assessing and accessing health information on the internet. J Clin Diagn. 2010;4(1):2153-2157.

28. World Health Organization. WHO Drug Information. Available from: https:/www.who.int/medicines/publications/druginformation/en/. Accessed September 19, 2019.

29. HINARI. Hinari Access to Research for Health programme. Available from: https://www.who.int/hinari/en/. Accessed September $19,2019$.

30. MedicinesComplete. MedicinesComplete. Available from: https:// about.medicinescomplete.com/. Accessed September 19, 2019.

31. Mero Pharmacist. Available from: https://meropharmacist.com/ Accessed. AccessedSeptember 19, 2019.

32. Shrestha S, Palaian S, Shrestha B, Santosh K, Khanal S. The potential role of social media in pharmacovigilance in Nepal: glimpse from a resource-limited setting. J Clin Diagn Res. 2019;13:3.

33. World Bank. Climbing higher: toward a middle-income Nepal Available from: https://www.worldbank.org/en/region/sar/publication/climbinghigher-toward-a-middle-income-country. Accessed February 20, 2020.

34. Jahanshir A, Karimialavijeh E, Sheikh H, Vahedi M, Momeni M. Smartphones and medical applications in the emergency department daily practice. Emerg (Tehran). 2017;5(1):e14-e14.

35. Ventola CL. Mobile devices and apps for health care professionals: uses and benefits. P T. 2014;39(5):356-364.

36. Nepali Telecom. 2019. Available from: https://ntc.net.np/. Accessed September 19, 2019.

37. Watkinson-powell A, Lee A. Benefits of an electronic medical records system in rural Nepal. JNMA. 2012;52(188).

38. Kruse CS, Smith B, Vanderlinden H, Nealand A. Security techniques for the electronic health records. J Med Syst. 2017;41(8):127. doi:10.1007/s10916-017-0778-4

39. Grajales FJ 3rd, Sheps S, Ho K, Novak-lauscher H, Eysenbach G. Social media: a review and tutorial of applications in medicine and health care. J Med Internet Res. 2014;16(2):e13. doi:10.2196/jmir.2912

40. Thakur DN. Social media: opportunity or threat to public health in context of Nepal. Health Prospect. 2017;16(1):7-9. doi:10.3126/ hprospect.v16i1.17099

41. Bernhardt JM, Alber J, Gold RS. A social media primer for professionals: digital dos and don'ts. Health Promot Pract. 2014;15 (2):168-172. doi:10.1177/1524839913517235

42. George DR, Rovniak LS, Kraschnewski JL. Dangers and opportunities for social media in medicine. Clin Obstet Gynecol. 2013;56 (3):453-462. doi:10.1097/GRF.0b013e318297dc38

43. Iftikhar R, Abaalkhail B. Health-seeking influence reflected by online health-related messages received on social media: cross-sectional survey. J Med Internet Res. 2017;19(11):. doi:10.2196/jmir.5989.

44. Al Khaja KAJ, AlKhaja AK, Sequeira RP. Drug information, misinformation, and disinformation on social media: a content analysis study. J Public Health Policy. 2018;39(3):343-357. doi:10.1057/ s41271-018-0131-2

45. Health InSite. Available from: http://www.healthinsite.net/his/home. Accessed November 1, 2019.

46. Masic I, Miokovic M, Muhamedagic B. Evidence based medicine - new approaches and challenges. Acta Inform Med. 2008;16(4):219-225. doi:10.5455/aim.

47. Sathian B. Is the science in right direction? Pitfalls of evidence based medicine in Nepal. Kathmandu Univ Med J. 2015;13(4):279-280. doi:10.3126/kumj.v13i4.16823

48. Hamrosi KK, Raynor DK, Aslani P. Enhancing provision of written medicine information in Australia: pharmacist, general practitioner and consumer perceptions of the barriers and facilitators. BMC Health Serv Res. 2014;14:183. doi:10.1186/1472-6963-14183 
49. Wells L, Metherell M. Consumer medicine information. Aust Prescr. 2017;40(2):44-45. doi:10.18773/austprescr.2017.015

50. Winterstein AG, Linden S, Lee AE, Fernandez EM, Kimberlin CL. Evaluation of consumer medication information dispensed in retail pharmacies. Arch Intern Med. 2010;170(15):1317-1324. doi:10.1001/ archinternmed.2010.263

51. Kuehn BM. FDA weighs limits for online ads. JAMA. 2010;303 (4):311-313. doi:10.1001/jama.2009.1961

52. Greene JA, Herzberg D. Hidden in plain sight marketing prescription drugs to consumers in the twentieth century. Am J Public Health. 2010;100(5):793-803. doi:10.2105/AJPH.2009.181255

53. Abel GA, Penson RT, Joffe S, Schapira L, Chabner BA, Lynch TJ Jr. Direct-to-consumer advertising in oncology. Oncologist. 2006;11 (2):217-226. doi:10.1634/theoncologist.11-2-217

54. Zachariah CS, Sowmya C, Thomas D, Reddy YP. Assessment of adherence to drug information service protocol in a rural Indian Hospital. AJBPS. 2013;3(25):27-31.

55. Reppe LA, Spigset O, Schjøtt J. Drug information services today: current role and future perspectives in rational drug therapy. Clin Ther. 2016;38(2):414-421. doi:10.1016/j.clinthera.2015.12.019
56. Shankar PR. HINARI: Providing Access to Scientific Literature in Resource Constrained Settings. 2011.2(10).

57. Vidotti CCF. Drug information centers in developing countries and the promotion of rational use of drugs: a viewpoint about challenges andperspectives. Int Phar J. 2004;18(1):21-23.

58. Patel H, Churi S, Gurumurthy P, Madhan R. Quality assurance of drug information service and drug therapy review provided by clinical pharmacists in an Indian teaching hospital. Indian J Pharm Pract. 2015;8(3):117. doi:10.5530/ijopp

59. Ahirwar CS, Mishra AK, Pathak AK. A need to be fulfilled: drugInformation services. IOSR J Pharm. 2017;7(6):15-19. doi: 10.9790/3013-0706011519

60. Dargahi H, Khosravi S. Hospitals pharmacy quality assurance system assessment in tehran university of medical sciences, Iran. Iran J Public Health. 2010;39(4):102-113.

61. Rajanandh MG, Seenivasan P, Ahalya SP, Anjali R. Assessment of pharmacists-led drug information service in a tertiary care hospital in India. J Med Sci. 2017;17(2):102-106. doi:10.3923/jms.2017.102.106
Journal of Multidisciplinary Healthcare

\section{Publish your work in this journal}

The Journal of Multidisciplinary Healthcare is an international, peerreviewed open-access journal that aims to represent and publish research in healthcare areas delivered by practitioners of different disciplines. This includes studies and reviews conducted by multidisciplinary teams as well as research which evaluates the results or conduct of such teams or healthcare processes in general. The journal

\section{Dovepress}

covers a very wide range of areas and welcomes submissions from practitioners at all levels, from all over the world. The manuscript management system is completely online and includes a very quick and fair peer-review system. Visit http://www.dovepress.com/testimonials. php to read real quotes from published authors. 